\section{EL MUNDO CLÁSICO EN LA LITERATURA FEMENINA DE} VANGUARDIA

CLASSICAL WORLD IN AVANT-GARDE FEMALE LITERATURE

Victoria Sendón de León Universidad de Sevilla

Resumen:

Abstract:

Hoy en día, la tradición grecorromana Currently, the Greco-Roman tradition is está totalmente establecida en la cultura completely established in West culture. The occidental. El mundo clásico ha invadido la classical world has invaded Avant-Garde literatura de Vanguardia; personajes, acciones literature; characters, actions and events fill y acontecimientos llenan las hojas de obras, the pages of these works, as well poetry as tanto poéticas como narrativas, recreando narrative, recreating and representing the y representando asi el mito clasico de una classical myth in a different way throughout yepra completamente distinta a tra las propias autoras.

Palabras claves:

Safo, poema, mujer, escritora.

KEY WORD:

Sappho, poem, woman, female writer.
Si el pensamiento intenta descifrar la clave última del mundo, la poesía busca desesperadamente las palabras que expresen la experiencia de esa búsqueda. Sin embargo, el mundo no deja de ser más que mi propia representación del mundo, como diría Schopenhauer, -como dirían también los Vedas y como hoy lo confirma la física cuántica y la neurología-, porque lo que vemos no responde tanto a la manifestación de la realidad, como a su encubrimiento. Ése encubrimiento es lo que ha dado origen tanto al arte como a la filosofía. Es el secreto (Sekretirem) lo que nos desvela lo importante y significativo, siguiendo con Schopenhauer. Y ese secreto no puede ser otra cosa que el fundamento último del conocimiento a través de la percepción.

Se ha discutido hasta el infinito si existe o no una escritura propiamente femenina, lo que no se ha hecho, por cierto, respecto a la masculina, porque se supone que la representación colectiva y cultural del mundo es masculina: es "la" representación. De muchas culturas y de muchas épocas no sabemos nada del arte ni del pensamiento femenino porque no han trascendido al ámbito del reconocimiento y, por tanto, de la historia. Simplemente han sido ignorados, cuando no negados o destruidos. Consideración aparte sería que a las mujeres se les haya negado el acceso a la alta cultura. En otras épocas había que ser monja para poder escribir, porque sólo una mujer apartada de la institución de la familia patriarcal y de la responsabilidad de alumbrar y de criar unos hijos podía expresar su talento a través de la escritura, vedada en muchos casos a las damas de la corte, dedicadas a su oficio de tales, y más a la clase plebeya, que no tenía acceso en absoluto a dicho refinamiento.

Sin embargo, han existido momentos cumbre en los que esa obra de las mujeres sí ha trascendido. Y, sin duda, contiene matices que le son propios. ¿Por qué? Porque el cómo realmente conocemos el mundo no es desde nuestros sentidos, sino desde la experiencia mismadel cuerposocializado.Ynilaexperiencia deun cuerpode mujerni su socialización son las mismas que las experiencias del cuerpo socializado del hombre. La experiencia del propio cuerpo socializado es como un gran ojo que observa la realidad. La diferencia del punto de partida es evidente. La episteme que nos socializa sería, en todas esas épocas, la ideología androcéntrica y patriarcal, lo que trato de mostrar en este somero trabajo. Voy a comparar, pues, la poesía masculina y femenina de la lírica griega y de principios del siglo XX, lo cual no demuestra nada, sólo muestra representaciones diferentes del mundo, diferencias que, pienso, no son sólo personales, sino de género.

afo y Alceo 
En primer lugar compararé a dos poetas que vivieron en la misma época y que pertenecen a la misma cultura. Los dos en el siglo VI a.C. , y ambos de Mitilene, capital de la isla de Lesbos: Safo y Alceo Bajo el epígrafe de la "lírica", se encuentran diferentes métricas y temáticas en la poesía griega: el yambo, la elegía, los poemas monódicos, los corales, las odas y los epigramas. El adjetivo lyriká sólo indica que tales poemas podían cantarse al son de la lyra. La lírica monódica de la época arcaica está representada por Safo, Alceo y Anacreonte. Entre los dos primeros contrasta el carácter ardiente y belicoso de Alceo con el de Safo, más melancólico y sensible. En el llamado amor sáfico o lésbico se conjugan la pasión y el sentimiento femenino con un cierto aspecto ritual, dentro de unos círculos de mujeres que no han sido bien precisados, y que constituyen el ambiente que reflejan los poemas de Safo. Una poesía de sutiles matices, de colores brillantes, referencias a la naturaleza, a las fiestas lunares.

"Las cretenses entonces de este modo armonioso

con pies gráciles danzaban en torno al bello al tar

con pies grac

\{Safo, 15 (94 D)\}

La referencia a Creta no es una cuestión aleatoria, sino fundamental. Desde que el arqueólogo Arthur Evans matriarcal de Europa a partir de sus excavaciones, no podemos, y Marija Gimbutas interpretó la antigua religió que Safo recoge en sus poemas como heredera de aquella tradición.

\footnotetext{
"Aquí ven, a este templo sacrosanto de Creta,

donde hay un gracioso bosquecillo sagrado

de manzanos, y en él altares perfumados

con olor de inicenso.

Aquí el agua fresca murmura por las ramas

de manzano, y todo el recinto está sombreado

de manzano, y todo el rinto está sombreado

por rosales, y en su follaje que la brisa orea

se destila sopor.

Aquí el prado donde pacen los caballos ya está

florido con flores de primavera, y soplan

suavemente las brisas..

Acude, pues, tú, Cipris, coronada de guirnaldas,

para verter grácilmente en nuestras copas de oro

el néctar que ya está aderezado y escáncialo

en nuestros festejos."

\{Safo, 4 (5-6 D) $\}$
}

La referencia a los cultos en honor de la Diosa Madre, que en Creta no es si no la diosa de las serpientes, es una constante en Safo, aunque siempre invocando a Cipris -Afrodita- la diosa del amor Es frecuente que Safo contraponga el amor a la guerra, es decir, un mundo más propiamente femenino al belicoso masculino, que se enardece con tropas y armamento, con barcos y carros de combate y en contraste con los poemas de sus coetáneos, que recuerdan vagamente aquel espíritu que sobrevirá por siglos en el patriarcado, como cuando Filippo Tomaso Marinetti proclamaba: "Es más bello un coche de carreras que la Victoria de Samotracia".

"Dicen unos que un ecuestre tropel, la infantería

otros, y ésos, que una flota de barcos resulta

lo más bello en la oscura tierra, pero yo digo

que es lo que uno ama.

Y es muy fácil hacerlo comprensible a cualquiera.

pues aquella que mucho en belleza aventajaba

a todos los humanos, Helena, a su esposo

un principe ilustre,

lo abandonó y marchóse navegando hacia Troya,

sin acordarse ni de su hija ni de sus padres

en absoluto, sino que la sedujo Cipris.

También a mí ahora a mi Anactoria ausente

me has recordado.

Cómo preferiría yo el amable paso de ella

y el claro resplandor de su rostro ver ahora

a los carros de guerra de los lidios en armas

marchando al combate."

$\{($ Safo, 6 (17 D) $\}$

En cambio, la lírica de Alceo es un tanto bronca: amenazas de tormenta, de traición, de violencia y de muerte se entrelazan con imágenes más vitalistas, como el vino y la fiesta compartidos por verdaderos camaradas.

"De nuevo esta ola, como la de antes, avanza

contra nosotros, y nos dará mucho trabajo

resistirla cuando aborde nuestra nave.

...Aprestemos la defensa lo antes posible

y corramos al amparo de un puerto seguro.

Que a ninguno de nosotros la duda cobarde

le acose. Claro está que es enorme el empeño.

Recordad las fatigas que antaño soportamos.

Y que ahora todo hombre demuestre su valia.

Con que no avergoncemos por falta de coraje

a nuestros nobles padres que yacen bajo tierra."

\{Alceo, $1(119 \mathrm{D})\}$

La camaradería, el amor entre amigos, es una constante en la realidad y en la mitología griega. No existe un solo héroe que no tenga un partener masculino: Heracles y Yolao, Teseo y Pirítoo, Aquiles y Patroclo, Orestes y Pílades... También sabemos que cuando fueron aniquilados los griegos tebanos por los macedonios en la batalla de Queronea, aquellos yacían en el campo de batalla entrelazados de dos en dos como parejas de amantes que eran. Este telón de fondo constituye el ambiente propio que refleja Alceo en alguno de sus poemas:

"Bebe y emborráchate, Melanipo, conmigo. ¿Qué piensas?

¿Qué vas a vadear de nuevo el vorticoso Aqueronte,

una vez ya cruzado, y de nuevo del sol la huz clara

una ver? ya ?amos, yo de nuevoñes del la luz clara

En efecto, también Sísifo, rey de en tas eoris, querfias.

En efecto, tambien Sisifo, rey de los colios, que a todos

superaba en ingenio, se jactó de escapar a la muerte. 
$Y$, desde luego, el muy artero, burlando su sino mortal, dos veces cruzó el vorticoso Aqueronte. Terrible

y abrumador castigo le impuso el Crónida más tarde

bajo la negra tierra. Con que, vamos, no te ilusiones.

Mientras jóvenes seamos, más que nunca, ghora importa

Mientras jovenes seamos, más que nunca, ahora impor ta

\{Alceo, $3(73 \mathrm{D})$ \}

Esta introducción me sirve para constatar que determinadas constantes se repiten a lo largo de los siglos.

\section{Poesía sáfica del Siglo XX}

A principios del siglo XX, durante la Primera Guerra, en el período de entreguerras, la Segunda Guerra y la postguerra conviven en Europa diversas vanguardias literarias y artísticas que configuran un mosaico sorprendente de creación revolucionaria en estos campos. Se trata de un período intenso en el que confluyen grandes avances tecnológicos (la electricidad, la radio, el cine, la aviación o el teléfono) con una euforia creativa y rompedora con los cánones anteriores del realismo literario y del simbolismo así como con el impresionismo pictórico como pocas veces ha sucedido en la Historia.

Una fecha representativa es la de 1907, en que Picasso pinta Les demoiselles d'Avignon en su estudio del Bateau Lavoir en Montmatre (París) con el que se inicia el cubismo pictórico, al que le sigue el literario con Apollinaire. El futurismo ya había sido iniciado por Marinetti, y posteriormente irrumpe el dadaísmo, proclamado en Zürich en 1916 por Tristan Tzara en el café Voltaire. Luego le seguirá el surrealismo, que nace de las cenizas de dadá, y cuyo santón será André Breton. En Berlín se impone el expresionismo, del que derivará "la nueva objetividad" y la Bauhaus. Después de la Segunda Guerra, también en París, se pone de moda el existencialismo de Sartre y Simone de Beauvoir. Si En busca del tiempo perdido de Marcel Proust supone el adiós a todo lo anterior, el Ulises de James Joyce representa la ruptura por excelencia con aquel mundo perdido.

Es un mundo convulso en el que París y otras ciudades europeas se llenan de artistas expatriados, como Ezra Pound o Hemingway, que tan bien refleja el ambiente de la época en su obra París era una fiesta. Muchas mujeres artistas también se unirán a esos movimientos, como Gertrude Stein al cubismo literario o pintoras como Leonora Carrington o Remedios Varo alcanzarán cimas sorpendentes en la expresión surrealista de sus propios fantasmas. Otras muchas colaboran como editoras o libreras con los movimientos nacientes, Adrienne Monnier o Sylvia Beach. Janet Flanner escribe su crónica semanal en Carta desde París para el New York Times. Hilda Doolittle inicia el "imaginismo" junto a Pound en Londres; Colette -suplantada durante años por su marido Wily-, obtendrá un éxito popular sin precedentes. Pero otras muchas, apiñadas y dispersas en la Rive Gauche parisina, rompen moldes en su calidad de escritoras. Tal vez la más señera sea Djuna Barnes, que sorprende y escandaliza con Nightwood. Natalie Clifford Barney se convierte en la gran anfitriona de las vanguardias en su casa de la rue Jacob con su Templo de la amistad. A estos círculos pertenece Renée Vivien, de la que vamos a comentar algunos rasgos de su obra.

A Pauline Mary Tarn se la ha llegado a llamar "Safo 1900", una autora que conocemos como Renée Vivien, un nombre ambiguo por su pronunciación, y fruto de un acto de rebeldía de esta joven nacida en Londres en 1877, que cambió su nombre y su lengua como protesta contra la Inglaterra victoriana y contra el yugo ejercido por su egótica madre. Su padre murió cuando ella tenía nueve años, pero su herencia permitió que la madre enviara a Pauline a educarse en distintos internados entre Inglaterra y Francia. Precisamente ahí, en un pensionado de Fontainbleau, arraigó su amistad con Violette Shillito, una verdadera niña prodigio de carácter independiente y de inteligencia curiosa y despierta, que transmitió a Pauline su pasión por la literatura francesa, de modo que a los dieciséis años comienza a hacer sus primeros pinitos en la escritura de poemas en francés. Nada más obtener la mayoría de edad, a los ventiún años, se instala en París. Y será su amiga Violette la que le presente, en 1899, a la que será el gran amor de su vida: Natalie Clifford Barney, la Amazona. Muy pronto inician una apasionada y tormentosa relación, ya que sus caracteres son tan dispares que se hace muy difícil establecer una armonía entre ellas. Pauline, lánguida, melancólica, extremadamente sensible, solitaria... Y Natalie, fuerte, vital, extravertida, sociable, seductora impenitente... Sin embargo, en esos seis años de amargas rupturas y apoteósicos reeencuentros, escribirá Pauline su mejor poesía. En 1901 publica Estudios y Preludios, ya desde entonces con el nombre de Renée Vivien. El triste contrapunto será la muerte de su amiga Violette, lo que le produce una honda desesperación, que contribuye a que busque refugio en la poesía, comenzando un período de febril creatividad, a lo que contribuye también las numerosas aventuras de Barney, y que desemboca en su ruptura en 1906. Ahí es cuando comienza su decadencia física y mental, a pesar del apoyo emocional de la baronesa Hélène de Zuylen o de la admiración epistolar de la princesa turca Kérimé TurkhanPachá. Renée Vivien vivía sola en su apartamento de la Avenue du Bois rodeada de dioses paganos y objetos exóticos, aromas de incienso y a la luz de las velas, ya que los postigos de sus ventanas estaban siempre cerrados. Escribía también en un cementerio abandonado, imagen de su propio abandono al alcoholismo y a la anorexia, lo que acabó con su vida a los treinta y dos años en 1909. Si su poesía figura en la literatura de vanguardia, su espíritu respondía a un decimonónico romanticismo.

Las raíces literarias de Renée Vivien, aparte de en su propio imaginario femenino, habría que buscarlas en Baudelaire y en Safo, sobre todo por su necesidad de cimentar un ideal lésbico con cierto aire mediterráneo. 
El "poeta maldito" de Las flores del mal constituye un claro precedente de los temas lésbicos, censurados mil veces por la Iglesia y escándalo insuperable para la burguesía timorata de finales del XIX. Su vida disipada y bohemia provoca reacciones de repulsa entre su familia, comme il faut, que reniega de él. Pero Charles Baudelaire es un rebelde, como luego lo será Renée Vivien, pero en un estilo más masculino. Su malditismo no proviene únicamente de su producción literaria, sino también de su vida bohemia, envuelta en drogas y prostitución.

LESBOS

"Madre de los juegos latinos y voluptuosidades griegas,

Lesbos, en la que los besos, lánguidos y gozosos,

Cálidos como soles, frescos como sandías,

Constituyen el ornato de noches y días gloriosos;

Madre de los juegos latinos y de las voluptuosidades griegas,

Lesbos, donde los besos son como cascadas

Que se vuelcan sin temor en los abismos insondables..."

(Poema no 2 de Los despojos en Las flores del mal)

Renée Vivien retoma esta temática, cuya fuente de inspiración la constituye su propia relación con la Amazona, -es decir, con Natalie Barney- apelativo con resonancias poderosas de la propia Artemisa, otra diosa rebelde e indómita que amadrinará para siempre a las aguerridas amazonas en su lucha contra las imposiciones patriarcales: Pentesilea, Mirinda, Hipólita, Etíope... En el poema Amazona, Renée Vivien refleja en cierta medida su visión de la amante que la domina, la somete y, sin embargo, la seduce de tal modo que la hace víctima de sus antojos, de su modo de amar:

\section{AMAZONA}

"La amazona contempla a sus pies las ruinas,

en tanto el sol, cansado del combate, se duerme;

Aromas de masacre excitan sus sentidos

$Y$ del monstruoso amor de la Muerte se embriaga.

Sólo halla dulce el beso de unos labios que expiran.

$Y$ que en su ardiente boca dejan regusto a sangre:

Paladeando el perfume del campo de batalla

Su arrogante deseo se aviva y palidece.

Fiera amante de quienes le procuran el goce

De su atroz agonía y de su acerba muerte

Menosprecia la miel de la caricia insulsa,

Sólo aplaca su sed el cáliz del horror.

El estertor la arrastra a un delirio salvaje,

Su corazón se inflama al fragor de la lucha

$Y$, leona de ojos de oro ebria de destrucción

El lívido sudor de las frentes la excita.

Ríe de placer ante el pálido vencido,

Y en su capa teñida de púrpura, al ocaso,

Se arroba contemplando el espasmo supremo,

Más terible y hermoso que el espasmo de amor."

[ 2006: 117]

Para Renée Vivien, el amor se convierte en una lenta muerte que tiene algo de ofrenda a una diosa oscura, más de thánatos que de eros, la otra cara de las divinidades femeninas que la mitología ha consagrado como inseparables. Es el caso de Isthar y Erskigal, hermanas gemelas que representan la vida y la muerte en la cultura sumeria pero que quedan subsumidas en la original Innana; al igual que Atenea y Medusa, una de las Gorgonas, cuya cabeza segada por Perseo petrificaría a todo hombre que osara mirarla.

\section{TO THE SUNSET GODDES}

"La ojarasca de otoño evocan tus cabellos,

oh, Diosa del ocaso, de la noche y las ruinas,

la sangre del crepúsculo es tu roja corona

Y en aguas cenagosas te complace mirarte.

Olor a ramas pútridas y azucenas marchitas

desprenden los festones de tu manto; tus ojos

persiguen blandamente ensueños desvaídos

y tu voz aguarda un eco de lágrimas de adiós.

Musa de todo cuanto languidece y declina,

Pasiva e indiferente al dolor implacable.

que acendrara en tu cuerpo esa divina pose,

pareces deslizarte en un aura irreal.

¡Ah, la pasión quebrada, ah, la sabia agonía

iAh, la pasion quebrada, ah, la sabia agonia
de tu ser que en el goce expira! ;Ah, postreros

de tu ser que en el goce expira! ¡Ah, postrer
espasmos! En el fondo del placer infinito,

paladeo el sabor violento de la muerte."

[2006: 57]

Si comparamos la poesía de Renée Vivien con la de otro poeta y amigo, que trata el tema lésbico desde una perpectiva más ajena, Pierre Louÿs en Las Canciones de Bilitis, podemos comprobar que su visión de otusider no alcanza a expresarse con la misma hondura ni con el sentimiento desgarrado de Vivien. Este autor era un poeta belga amigo de André Gide, quien le introdujo en los círculos literarios de París. Él mismo inventó el personaje de Bilitis y se hacía pasar por traductor de sus poemas. Supuestamente se trataba de una poeta de padre griego y madre fenicia, cuya tumba fue descubierta por un inexistente arqueólogo alemán también inventado. Según esta leyenda había sido alumna de Safo en la misma ciudad de Mitilene, quién le enseñó el arte del amor y del canto. Cuando allá perdió su amor, se trasladó a la isla de Chipre, lugar originario de Afrodita, donde terminó siendo sacerdotisa de la diosa. Estos poemas tienen mucho más de sensualidad que de desgarro, más de paisaje heleno que de tragedia personal.

"iAy! Si pienso en ella, mi garganta se reseca, mi cabeza cae, mis senos se endurecen y me duelen, tiemblo y lloro caminando.

Si la veo, mi corazón se para, mis manos tiemblan, mis pies se hielan, un rubor de fuego Si la veo, mi corazon se para, mis manos tiemblan,
sube a mis mejillas, mis sienes baten dolorosamente.

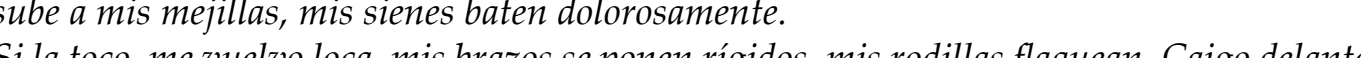
Si la toco, me vuelvo loca, mis brazos se ponen rígidos,

de ella y me acuesto como una mujer que va a morir.

De todo lo que me dice, me siento herida. Su amor es una tortura y los que pasan por la calle oyen mis quejas... jAy! ¿Cómo la puedo llamar la Bien Amada?"

[Las canciones de Bilitis, 2006: 91] 
La alusión a las diosas es frecuente, con esa familiariedad entre lo divino y lo humano tan propia del espíritu de una paganidad naturalista y deshinibida, que contrasta con la gravedad y la distancia de los hombres con los dioses monoteístas. Astarté es la diosa del amor fenicia, equivalente a la Afrodita griega, aquella diosa a la que Salomón levantó un altar después de su ardorosa relación con Bilkis, la legendaria reina de Saba. LAS SACERDOTISAS DE ASTARTÉ

"Las sacerdotisas de Astarté hacen el amor cuando se alza la luna. Luego ellas se levantan y se bañan en una

gran alberca con brocales de plata.

Con sus curvados dedos peinan sus cabelleras y sus manos, tintadas de púrpura, enredadas en sus bucles

negros, parecen ramas de coral en un mar sombrío y flotante.

No se depilan nunca, para que el triángulo de la diosa marque su vientre como un templo. Pero se tintan al

pincel y se perfuman profundamente.

Las sacerdotisas de Astarté hacen el amor cuando se oculta la luna, luego, en una sala tapizada donde arde, en

el techo, una lámpara de oro, se acuestan al azar."

[O.C. 2003: 121]

\section{LA ILIADA Y LA OdISEA COMO FUENTES DE INSPIRACIÓN}

Es curioso que a comienzos del siglo XX las vanguardias retomen los libros más arcaicos de nuestra civilización occidental como fuentes de inspiración: La Iliada y la Odisea. También me llama la atención que sean dos escritores, James Joyce y Ezra Pound, los que elijan la Odisea como arquetipo literario de libro de aventuras y de creación poética, y que sea una mujer, Hilda Doolittle, la que se inspire en un poema mucho más bélicoso como la Iliada. En este caso voy a comparar a Ezra Pound con Hilda Doolittle : porque los dos son americanos, porque los dos se trasladan a vivir en Europa, porque fueron amantes cuando Hilda era aún muy joven, y porque el primer libro de Pound fue Hilda's Book. Después romperían su compromiso porque Hilda comenzó una relación con una joven estudiante, Frances Gregg, con la que viajaría a Europa. En Londres, se encontraron de nuevo Hilda y Ezra, que acudía a las reuniones de poetas organizadas por él mismo. Allí conocería al que sería su marido, Richard Aldington, presentado por su reciente amante, Brigit Patmore.

Después de un tiempo de estar en Inglaterra, Doolittle enseñó sus poemas a Pound, que por entonces se estaba inspirando en las formas poemáticas china y japonesa de tanka y haiku, y quedó sorprendido al comprobar cómo Doolittle iba por el mismo camino, inventando para ella el término de "poeta imaginista". El imaginismo se caracteriza por el verso libre y la concisión, utilizado también como un revulsivo contra los poetas simbolistas, considerados decadentes. Pero, aunque los modelos de la poesía imaginista se basaran en la poesía japonesa, el modo de escribir de H.D. se acercaba más a la lírica grecolatina, especialmente a los poemas de Safo. La verdad es que Pound nunca dominó el chino, aunque lo traducía, pero Doolittle sí dominaba el griego clásico y de hecho tradujo Ifigenia en Áulide, Hypólito y El Ión de Eurípides. La poesía de sus comienzos fue juzgada por el crítico Harold Monro como "poesía insignificante", aunque más tarde sería la primera mujer galardonada con la medalla de la Academia Americana de las Artes y las Letras. Un crítico muy perspicaz y visionario, por cierto, el tal Monro. Para 1915 Pound ya había escrito la primera parte de su obra Cantos, considerada obra emblemática del imaginismo, mientras Doolittle se introducía en temas bélicos pero desde un punto de vista feminista, posiblemente por la traumática experiencia de que su marido, Richard Aldington, tuvo que ir a la guerra y a la vuelta era otro hombre. Mientras tanto, Hilda tiene amantes hombres y mujeres hasta que conoce a la escritora británica Bryher, Annie Winifred Elleman, que sería su compañera durante el resto de sus días, lo cual no le impidió tener relaciones varias al mismo tiempo, por ejemplo con el propio esposo de su amiga, McAlmon. Ésta tuvo luego un nuevo marido, Kenneth Macpherson, con quien vivirían las dos un ménage à trois también intelectual, ya que montaron la revista Close Up y formaron el grupo de cine POOL para escribir y producir películas. La única completa fue Borderline, en la que actuaba la propia Hilda. En 1933 H.D. viaja a Viena para psicoanalizarse con Freud, así como Bryher, paranoica ante el inminente estallido de una nueva guerra conducida por Hitler. De este análisis H.D. escribiría una trilogía con el título de Tribute to Freud.

Mientras, Ezra Pound había tomado otros derroteros. Tras una estancia en París en los efervescentes años veinte, en los que se relacionó con las vanguardias más rompedoras, como dadaístas y surrealista, en 1924 se trasladó a Italia donde terminaría siendo un ferviente admirador y propagandista de Mussolini hasta el punto de que fue hecho prisionero por los partisanos y entregado a los americanos, que lo encarcelaron en un centro de adiestramiento en Pissa, donde esbozó sus Cantos pisanos. Tras una vuelta a los EE.UU., regresó a Italia, instalándose en Venecia hasta su muerte. Fue muy criticado por sus ideas políticas, pero influyó enormemente en Allen Ginsberg y en toda la Beat Generation, especialmente en Jack Kerouac. También en el grupo español de "los novísimos". H.D. seguía escribiendo y buscando. Su obra Helena en Egipto ha sido considerada como una respuesta a los Cantos de Pound. Ella vivió en Zúrich donde murió en 1961 a los 75 años. Sus cenizas fueron trasladadas a su ciudad de Pennsylvania, enterradas en el panteón familiar con el siguiente epitafio:

"Puedes decir, Flor griega;

El éxtasis griego reclama para siempre

A aquellos que murieron

Siguiendo la medida perdida

De intrincadas canciones."

H.D. siempre se consideró como formando parte de una banda herética de artistas y trabajadores de la cultura, "portadores de la sabiduría secreta". En Helena en 
Egipto retoma dos personajes centrales de la Iliada, la propia Helena y Aquiles en Egipto, siguiendo la Palinodia de Estesícoro (un breve fragmento que se conserva en el Fedro de Platón) y, sobre todo, siguiendo la Helena de Eurípides, que transforma el drama de la guerra de Troya en una novelita medio rosa medio fantástica, ya que supone a la verdadera Helena en Egipto, donde ha sido trasnportada por el dios Hermes, y entregada a la custodia del rey Proteo, mientras que en Troya sólo habita la imagen fantasmal de una falsa Helena, por la que combaten los aqueos y resisten los troyanos. Sin embargo, en la Helena de H.D. las diferencias con el personaje de Eurípides son sustanciales. En éste, el único objetivo y sentido de Helena es la espera de su marido Menelao mientras permenece absolutamente fiel a su memoria: "Sabe que he conservado para ti mi lecho intacto", [1985: 795] hasta que el rey de Esparta arriba a las costas egipcias como superviviente de un terrible naufragio. A través de un mensajero se descubren el uno al otro, así como el engaño, la ilusión sufrida tras las huellas de un fantasma: " $¡ Y$ creí yo que fuiste a la ciudad del Ida y a las inútiles murallas de Ilión! Por los dioses, ¿cómo te arrebataron de mi morada?" [2007: 660] . Por el contrario, en Helena en Egipto ni siquiera aparece Menelao, sino Aquiles. Aquiles y Helena son dos protagonistas y antagonistas a la vez con un destino que cumplir en solitario: "ambos están ocupados con el pensamiento de la reconstrucción, él en retomar la costa donde se encuentra la isla de Faros, ella en establecer o restablecer los antiguos Misterios".

".... icómo es que Helena en Egipto
y Helena en las murallas

etán juntas y sin embar

estan juntas y sin embargo separadas?

¿como se han cruzado los caminos?

¿cómo se han cruzado los círculos?

cómo expresar o como encuadrar el problema?

Yo, también, me lo pregunto y me lo planteo

aunque no estoy embelesado

como tú en éste templo de Amón

y raramente estoy aquí,

mientras trabajo para retomar la costa

donde se encuentra la isla de Faros,

pide al oráculo que revele,

Helena, cómo fue el sueño,

cómo era el velo de Citerea.

[2007: 95 $]^{1}$

Para H.D., Aquiles, más que un personaje arcaico, supone un laboratorio en el que diseccionar la psicología profunda del poder patriarcal. Helena, por el contrario, es la mujer protagonista que rescata al amante poeta de la figura del soldado. La transformación de Aquiles en el Nuevo Mortal comienza en la cima de su poder militar. "....qué congoja, que insaciable

dolor, ardiendo en sus tendones,

1 Citerea, además de ser una isla jónica, se refiere también a la diosa Afrodita, como en este caso. cuando recuerda la flecha

que robó la Inmortalidad

y le hizo Mortal (...)

iera inevitable la Guerra?"

[o.c. : 61]

La búsqueda última para H. D. sería cómo reconciliar griegos y troyanos, cómo desterrar para siempre la guerra de la vida de los hombres. La presencia, la evocación de la madre ¿sería suficiente para una nueva búsqueda? La mirada que el héroe intercambia con Helena evoca borrosos recuerdos de Tetis, la diosa oceánica, su Madre.

"... dices que este sueño al despertar
fue suficiente, hasta que su madre vino

Tetis u otra-era su madre

quien te convocó aqui

¿es su isla, Leuké,

o es la de Afrodita?no importa

querida Ni⿱ña, estamos juntos,

querida Nina, estamos juntos,

lejos de la Guerra,

[o.c. : 202]

En Helena en Egipto, H.D. querría deshacer la historia, que Troya nunca hubiera existido, que esa guerra por nada no hubiera tenido lugar, que el guerrero y la mujer sólo hubieran estado ligados por el amor, y, desde ahí, iniciar una nueva búsqueda. Es curioso cómo H.D. tomara como inspiración un libro de guerra para transformarlo en un canto al amor. Por el contrario, Ezra Pound se inspira en la Odisea, lejos ya del fragor guerrero, un libro de aventuras, que utiliza para narrar una guerra real que está a punto de ocurrir en Europa. Su tono es más autobiográfico y de crónica de un mundo que desaparece y se transforma. Todo su Canto está salpicado de acontecimientos y de citas literales del libro de Homero. En su Cantar I, toma el material de los cantos X y XI de la Odisea: Odiseo, por consejo de Circe, la reina-hechicera, se hace a la mar en busca de los Infiernos, el reino de Hades, para consultar al adivino ciego, Tiresias, el camino seguro para regresar a Itaca. En él se aprecian ciertas analogías con la Divina Comedia. Algunos críticos consideran que este cantar tiene algo de profético, en cuanto que Pound también perdería a todos sus compañeros años más tarde, tras su implicación con el fascismo en la Segunda Guerra Mundial.

"Y bajamos a la nave,

Enfilamos quilla a los cachones, nos deslizamos en el mar

Divino, e

Izamos mástil y vela sobre aquella nave oscura (...)

Llegamos entonces al confín del mar más hondo

A las cimerias tierras, y ciudades pobladas

Cubiertas por la niebla de tejido espeso, jamás penetrado (...)

Y en el reflujo del océano, llegamos después al sitio

Predicho por Circe.

Aquí los ritos de Perimedes y Euríloco,

Y de mi cadera retirando la espada 
Cavé la fosa midiendo un ana en cuadro.

E hicimos libaciones sobre cada muerto (...)

Para el sacrificio, levantando una pira con efectos,

Una oveja para Tiresias sólo, negra y con cencerro,

Sangre negra se derramó en la fosa (...)

Muchos hombres, desgarrados por las broncíneas puntas de las lanzas,

Despojos de batalla, con armas manchadas de sandre todavía.

Esta muchedumbre me cercaba; gritando,

Palideciendo, requerí más bestias de mis hombres:

Degollamos los rebaños, ovejas muertas por el bronce(...)

Mas el primero en llegar fue Elpénor, Elpénor nuestro amigo,

Insepulto, lanzado sobre la tierra vasta,

Extremidades que abandonamos donde Circe,

Sin derramar lágrimas por él, sin amortajar su cuerpo,

Porque cosas urgentes nos llamaban(....)

El tono es tan sangriento y lúgubre, que llama la atención cómo Pound eligió este epidosdio de "bajada a los infiernos" para comenzar un libro que hubiera podido tener un sesgo de aventura vital y retorno a la patria, más que de muertos insepultos y sacrificios cruentos. Es justo la actitud opuesta a la de Antígona para quien no había asunto más urgente que el de enterrar a su hermano Polinices. El contraste con los poemas de Hilda Doolittle es tan evidente que sería redundante comentarlo. $\mathrm{Y}$ en cuanto a poesía imaginista se refiere, sin duda que los poemas de H.D. son claramente más representativos que los de Pound.

Por fin aparece Tiresias, el adivino ciego:

"Sal de la fosa, déjame la bebida sangrienta

Para mis vaticinios.

Y dio un paso atrás,

$Y$ él, fortalecido con la sangre, dijo entonces:

'Odiseo regresará a través del rencoroso Neptuno, por oscuros mares,

Perdiendo a todos sus hombres"

[Cantos, 19885: 2 y ss.]

Con esta exposición comparativa entre autores y autoras, de la misma época y de semejante cultura, no he querido demostrar nada, porque intuyo que la simple acción de "mostrar" pone en evidencia la clara diferenciación de los imaginarios respectivos marcados por el género. Una vez terminado este estudio, intuyo que la sensibilidad lésbica podría ser aún más "femenina" que la expresada en la literatura de mujeres heterosexuales, pero es sólo una impresión, una hipótesis que negaría el carácter más varonil de aquellas.

REFERENCIAS BIBLIOGRÁFICAS

Benstock, S., Mujeres de la Rive Gauche, Lumen, Barcelona, 1992.

Doolittle, H., Helena en Egipto, Igitur, Montblanc, 2007.

Eurípides, Helena, en Tragedias, Gredos, Madrid, 1985.
García-Gual, C., Antología poesía lírica griega, Alianza, Madrid, 1989. Louys, P., Las canciones de Bilitis, Ediciones 29, Barcelona 2003.

----, Las canciones de Bilitis, Ediciones 29, Barcelona 2003.

Pound, E., Cantos, Cátedra, Madrid, 1985.

Vivien, R., Cenizas y polvo (Antología) Visor, Madrid, 2006. 